\title{
Reappearance of arteriovenous malformations after complete resection of ruptured arteriovenous malformations: true recurrence or false-negative early postoperative imaging result?
}

\author{
Rabih Aboukaïs, MD, ${ }^{1}$ Matthieu Vinchon, MD, PhD, ${ }^{1}$ Mathilde Quidet, MD, ${ }^{1}$ \\ Philippe Bourgeois, MD, ${ }^{1}$ Xavier Leclerc, MD, PhD, ${ }^{2}$ and Jean-Paul Lejeune, MD, PhD ${ }^{1}$ \\ Departments of ${ }^{1}$ Neurosurgery and ${ }^{2}$ Neuroradiology, Lille University Hospital, Lille, France
}

OBJECTIVE Ruptured arteriovenous malformations (AVMs) are often obliterated after emergency microsurgical treatment. However, some studies have reported AVM recurrence after the obliteration of ruptured AVMs. The authors report their experience with AVM recurrence after successful microsurgical treatment of ruptured AVMs.

METHODS The authors reviewed the medical data of 139 consecutive patients who underwent microsurgery at the authors' institution for ruptured AVM between 2002 and 2012. Each patient underwent a conventional cerebral angiography examination immediately after the surgery. Subsequent follow-ups were performed with MR angiography after 6 months, and, if there was no indication of AVM recurrence, patients were followed up with conventional cerebral angiography between 1 and 2 years after the treatment; pediatric patients were followed up until age 18 years. Recurrence was defined as new radiological evidence of an AVM at the site of a ruptured AVM or a new hemorrhage in patients with angiographically documented AVM obliteration on postoperative angiograms.

RESULTS The mean age of the patients at the time of ruptured AVM diagnosis was 30.8 years (SD \pm 5 , range 4-69 years), and 44 of the patients were younger than 18 years (the mean age at diagnosis in this pediatric subgroup was 11.4 years [range 4-17.9 years]). Complete AVM obliteration after the initial microsurgery was observed in 123 patients (89.5\%). Reappearance of an AVM was noted in 7 patients between 12 and 42 months after the treatment, and all of these patients were younger than 18 years. The recurrent AVM was located in an eloquent zone in 4 patients, and deep venous drainage was noted in 3 patients. Radiosurgery was performed in 6 of these patients, and 1 patient underwent another microsurgical procedure. The authors noted only one rebleeding due to an AVM recurrence during the latency period after radiosurgery.

CONCLUSIONS The recurrence of an AVM is fairly rare and affects mostly pediatric patients. Therefore, especially in children, long-term angiographic follow-up is required to detect AVM recurrence or an AVM remnant. The authors stress the need for discussion involving a multidisciplinary neurosurgical team to decide on treatment in cases of any AVM recurrence or remnant.

https://thejns.org/doi/abs/10.3171/2016.3.JNS152846

KEY WORDS arteriovenous malformation; recurrence; microsurgery; angiography; vascular disorders

$\mathrm{R}$ UPTURED cerebral arteriovenous malformations (AVMs) are life-threatening lesions, which often affect young patients. Ruptured AVMs are usually managed in urgent care to preserve vital functions, ensure good functional outcomes, and prevent rebleeding. Microsurgery, endovascular treatment, and radiosurgery in combination or alone represent distinct therapeutic options for ruptured AVMs. In a meta-analysis, van Beijnum and colleagues reported a higher rate of complete AVM obliteration after microsurgery $(96 \%)$ than after radiosurgery $(38 \%)$ or endovascular treatment $(13 \%) \cdot{ }^{29}$ However, microsurgery is also associated with higher mortality and

ABBREVIATIONS $A V M=$ arteriovenous malformation; $S M=$ Spetzler-Martin. 
morbidity rates. Discussion among multidisciplinary clinicians is therefore required to establish an optimal AVM management strategy that takes into account the clinical status of the patient, volume of cerebral hematoma, location of the ruptured AVM, AVM size, and presence of deep venous drainage. The aim of such a strategy is to preserve functional outcomes after AVM rupture and to achieve complete resection. In cases of voluminous intracerebral hematoma, a microsurgical procedure is sometimes performed as part of urgent care because hematoma evacuation and AVM resection can be achieved during the same procedure. Of note, after microsurgery, ruptured AVMs with high Spetzler-Martin (SM) grades have an increased risk for AVM remnants. ${ }^{18}$

Recurrence of an AVM is defined as a new hemorrhage or new radiological evidence of an AVM in a patient in whom an examination with conventional angiography soon after treatment had indicated complete AVM obliteration. Only a few studies have focused on postoperative AVM recurrences..$^{2,3,5}$ Although various hypotheses have been proposed, ${ }^{12}$ the mechanisms of these recurrences remain unclear. In addition, it is often challenging to tell a true recurrence from an AVM arising from a remnant because a postoperative angiogram taken soon after surgery may falsely indicate complete AVM obliteration in some cases; accordingly, later examinations might better detect an AVM residue. As reported by some authors, the risk for rebleeding persists in cases of AVM remnants or of AVM recurrence. ${ }^{2,12}$ For example, a review by Morgan et al. indicated that 18 out of 44 patients with AVM recurrence had a new hemorrhage. ${ }^{21}$

In this study, to help improve the understanding of AVM recurrence after treatment for ruptured AVM, we report on our experience with recurrence after initially successful microsurgery for ruptured AVM.

\section{Methods \\ Patient Cohort}

This retrospective series consisted of 167 consecutive patients who presented at our institution with ruptured AVM between 2002 and 2012. Of these patients, 28 who had undergone surgery with the aim of solely evacuating the hematoma without an attempt to remove the ruptured AVM were excluded from further analysis, resulting in a population of 139 patients. Emergency surgical procedures were performed in 41 cases of neurological deterioration due to a large intracerebral hematoma.

\section{Data Collection}

We recorded the age at diagnosis and the American Society of Anesthesiology ${ }^{26}$ and World Federation of Neurosurgical Societies ${ }^{16}$ scores before the patients were microsurgically treated for ruptured AVM. Functional outcomes in all patients were evaluated with the modified Rankin Scale score 3 months after the treatment. ${ }^{23}$ The AVM size and location were determined with CT angiography in only those patients who underwent emergency surgery (41 patients). When the treatment was delayed, a complete neuroradiological assessment with conventional angiography and cerebral MRI was performed (98 patients). Arte- riovenous malformations were classified according to the SM grading system. ${ }^{28}$

Immediately after the treatment, each patient was examined with conventional cerebral angiography to identify any ruptured AVM remnants. For clinical and radiological follow-ups, all patients underwent conventional cerebral angiography between 1 and 2 years postoperatively; in children, follow-up MR angiography examinations were performed at regular intervals until the patients reached adult age. A 3D conventional angiography examination was performed whenever an MR angiogram showed suspicious vascular formations. Recurrence was defined as a new hemorrhage or new radiological evidence of a brain AVM occurring at the site of a previous, ruptured AVM whose obliteration had been documented on postoperative angiograms.

\section{Results \\ Patient Cohort}

We included 139 patients (67 [48.2\%] male, 72 [51.8\%] female) treated for a ruptured AVM at our institution between 2002 and 2012 (Table 1). The mean age at the time of diagnosis was 30.8 years ( $\mathrm{SD} \pm 5$, range $4-69$ years), and $44(31.7 \%)$ of the patients were younger than 18 years (mean age at diagnosis in this pediatric subgroup 11.4 years [range 4.0-17.9 years]). The ruptured AVM was located in an eloquent area in 49 patients (35.2\%), and deep venous drainage was noted in 29 (20.9\%) cases.

\section{Long-Term Imaging Follow-Up}

The mean follow-up length after treatment was 26 months (range 0.2-160 months). Complete AVM obliteration after the microsurgery was observed in 123 patients $(88.5 \%)$. Early postoperative conventional angiograms showed an AVM remnant in 16 patients (11.5\%). An additional microsurgical procedure was performed in 14 of these patients, and an additional radiosurgery was performed in the other 2 patients. Complete AVM obliteration was observed in 133 patients (i.e., in the 123 patients undergoing initial microsurgery and in 10 of the patients undergoing additional microsurgery for an AVM remnant). Conventional angiography examinations conducted 1 year postoperatively or later (mean follow-up length 18.8 months) indicated AVM recurrence in 7 patients (5.0\%).

\section{Characteristics of Patients With AVM Recurrence}

All of the 7 patients with AVM recurrence after microsurgery treatment for ruptured AVM were younger than 18 years at the time of ruptured AVM diagnosis (Table 2), with a mean age of 9.4 years (range 5-13 years); the initial World Federation of Neurosurgical Societies score was $\geq$ III in 6 of these patients. The ruptured AVM was located in an eloquent area in 4 patients, and deep venous drainage was noted in 3 patients. The mean nidus diameter was $2.3 \mathrm{~cm}$, and none of the patients had an associated aneurysm. In all patients, the initial microsurgical treatment had been performed in urgent care after CT angiography (without a preoperative angiography examination). The modified Rankin Scale score at 3 months was $\leq 2$ in 6 patients and 3 in 1 patient. 
TABLE 1. Main patient characteristics

\begin{tabular}{cc}
\hline \multicolumn{1}{c}{ Variable } & Value \\
\hline Pts w/ ruptured AVM* & $139^{*}$ \\
\hline Mean age at Dx in yrs \pm SD (range) & $30.8 \pm 5(4-69)$ \\
\hline Pts w/ WFNS score >II (\%) & $72(51.8)$ \\
\hline Pts w/ SM grade $>$ II (\%) & $23(16.6)$ \\
\hline Pts w/ postop remnant (\%) & $16(11.5)$ \\
\hline Pts w/ postop recurrence (\%) & $7(5.0)$ \\
\hline
\end{tabular}

$\mathrm{Dx}=$ diagnosis; Pts $=$ patients; WFNS $=$ World Federation of Neurosurgical Societies.

* Of these patients, 44 were children.

Recurrence of an AVM was diagnosed on angiographic examinations between 12 and 42 months after the microsurgery (for an example, see Fig. 1). None of the patients had rebleeding of the AVM during the interval between the initial and follow-up angiographic follow-ups. All $\mathrm{AVM}$ recurrences were evaluated in a discussion involving a multidisciplinary neurosurgical team, which decided to treat 6 of the patients with radiosurgery and 1 patient with additional microsurgery. One patient presented with rebleeding due to the AVM recurrence during the latency period after the radiosurgery.

At the final follow-ups, complete obliteration of the recurrent AVM was observed in $4(57.1 \%)$ of the patients (3 after radiosurgery and 1 after microsurgery). As for the 3 remaining patients $(42.9 \%), 2$ were still in the latency period after the radiosurgery at the time of this writing, and 1 was to undergo additional microsurgery treatment.

\section{Discussion}

Postoperative recurrence of ruptured AVMs is rare among adults but not uncommon among pediatric patients. When considering only the patients younger than 18 years at the time of ruptured AVM diagnosis in the present series, the rate of recurrence after obliteration of ruptured AVM (17.5\%) appears to be higher than the rates reported in other series with cases of both ruptured and unruptured AVMs., ${ }^{3,5,21}$ We therefore conclude that longterm angiographic follow-up is required, especially in young patients, to prevent rebleeding after treatment for ruptured AVMs.

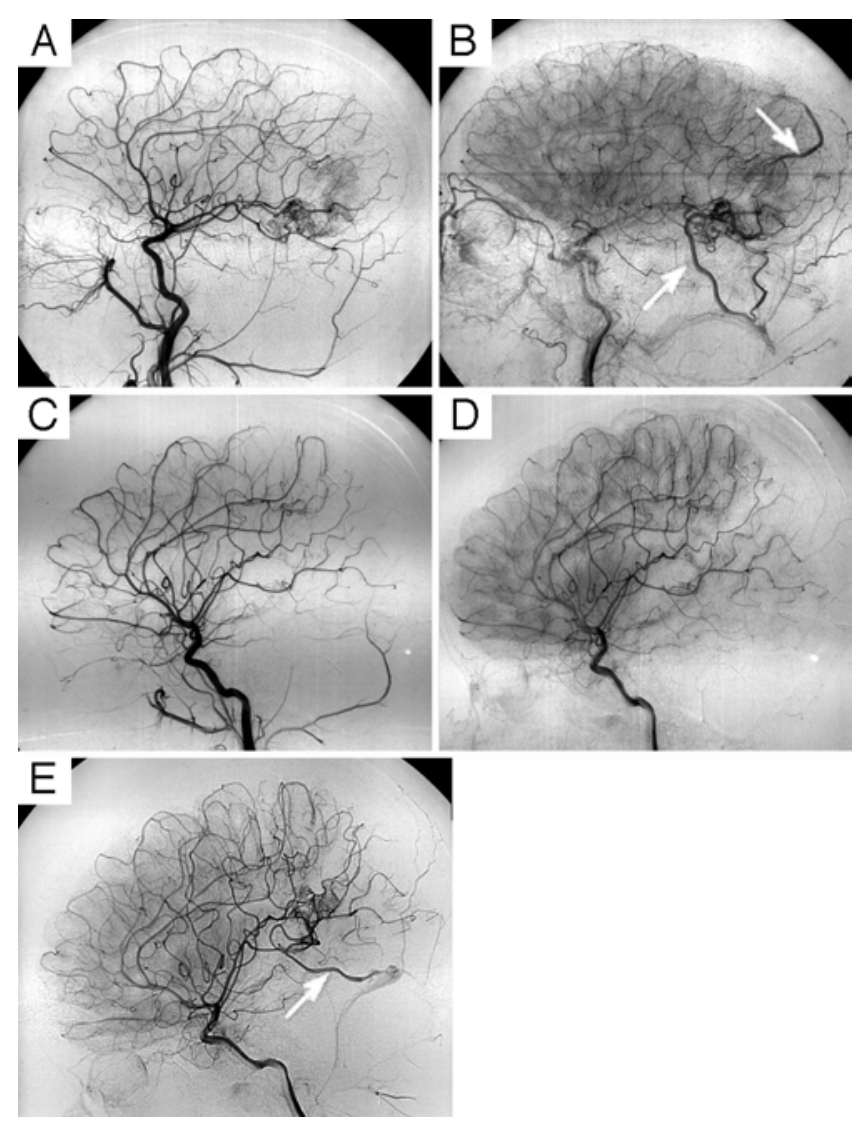

FIG. 1. Case 5. This patient presented with an SM Grade III ruptured AVM. Preoperative angiograms (very early arterial $[\mathbf{A}]$ and early arterial [B]) indicated 2 superficial venous drainages (arrow). Angiograms taken 7 days postoperatively (very early arterial [C] and early arterial [D]) showed a complete obliteration of the ruptured AVM and no early venous drainage. An angiogram taken after 1 year indicated AVM recurrence (E; arrow).

\section{True Recurrence or Missed Remnant?}

Conventional angiography is currently the gold standard for confirming complete AVM resection. ${ }^{3}$ The presence of a ruptured AVM is often accompanied by a voluminous hematoma, requiring emergency surgical evacuation. The visualization of an AVM remnant is therefore sometimes difficult on postoperative angiograms taken soon after the

TABLE 2. Characteristics of the patients with AVM recurrence

\begin{tabular}{cccccccc}
\hline $\begin{array}{c}\text { Case } \\
\text { No. }\end{array}$ & $\begin{array}{c}\text { Age at Dx of } \\
\text { Ruptured AVM (yrs) }\end{array}$ & $\begin{array}{c}\text { WFNS Score } \\
\text { at Dx }\end{array}$ & $\begin{array}{c}\text { SM Grade } \\
\text { at Dx }\end{array}$ & $\begin{array}{c}\text { Time From Tx to } \\
\text { Recurrence (mos) }\end{array}$ & $\begin{array}{c}\text { SM Grade of } \\
\text { Recurrence }\end{array}$ & $\begin{array}{c}\text { Tx Modality for } \\
\text { Recurrent AVM }\end{array}$ & $\begin{array}{c}\text { Complete } \\
\text { Obliteration }\end{array}$ \\
\hline 1 & 13 & III & II & $42^{*}$ & $\|$ & SRS & No \\
\hline 2 & 8 & II & II & 13 & III & SRS & Yes \\
\hline 3 & 11 & IV & II & 17 & $\|$ & SRS & Yes \\
\hline 4 & 6 & V & IV & 17 & III & SRS & Yes \\
\hline 5 & 10 & V & III & 12 & II & SRS & No \\
\hline 6 & 13 & IV & III & 12 & III & SRS & No \\
\hline 7 & 5 & IV & I & 18 & II & MS & Yes \\
\hline
\end{tabular}

MS = microsurgery; SRS = stereotactic radiosurgery; Tx = treatment.

* First postoperative angiogram at 21 months had shown no AVM remnant. 
treatment ${ }^{7,14}$ because a mass effect due to a postoperative residual edema or hematoma can mask a remnant of a ruptured AVM. Moreover, a focal vasospasm or thrombosis could be the reason for the absence of a visible residual AVM on angiograms taken immediately postoperatively. Accordingly, a later resolution of a vasospasm or recanalization of abnormal vessels could reactivate a hidden residual arteriovenous shunt.

The delayed development of abnormal vessels after ruptured AVM resection in children confirms that AVMs are not static, but result from an ongoing anomalous angiogenic process. Many theories have been proposed to explain this process. Some authors have suggested the model of the "hidden compartment" or "reserve nidus" of AVM recurrence. ${ }^{22,24}$ Others have suggested an angiogenic mechanism involving vascular endothelial growth factors in AVM recurrence. ${ }^{1,12,15,27}$ For instance, Sonstein et al. reported a higher level of local vascular endothelial growth factor in patients with AVM recurrence. ${ }^{27}$

Moreover, the AVM angioarchitecture in children differs from that in adults. In children, the vessels in AVM are immature and still growing via angiogenic mechanisms, which may explain why pediatric patients have an increased risk for AVM recurrence after surgery. It has also been reported that AVM recurrence is associated with deep venous drainage. ${ }^{3}$ Compared with adults, children are more likely to have a ruptured AVM with deep venous drainage and a larger nidus. ${ }^{9}$ Hetts and colleagues reported that exclusive deep venous drainage is more common in children $(28 \%)$ than in adults $(14 \%, \mathrm{p}<0.001) .{ }^{9}$ In our series, most children underwent emergency treatment and conventional angiography, and among the 7 patients with ruptured AVM recurrence, 3 had deep venous drainage. Thus, the presence of deep venous drainage should prompt monitoring for AVM recurrence for a longer time period.

Similarly, the presence of a residual perinidal angiopathy may mimic a residual nidus, and the presence of early venous drainage should be carefully investigated in such cases. Even without early venous drainage, we recommend angiographic follow-ups for longer periods of time in patients with a residual perinidal angiopathy, particularly in children, to monitor for AVM recurrence. A discussion between neuroradiologists and neurosurgeons is essential in such cases to develop an angiographic monitoring strategy.

The findings during the surgical procedure will play an important role in confirming the diagnosis of a postoperative AVM remnant. Intraoperative conventional angiography may also be performed as reported by Gaballah et al. in a series of 17 pediatric patients with 18 cerebral AVMs; ${ }^{6}$ in 2 of these patients, intraoperative angiography indicated a residual AVM, and resection was completed in both cases, with no recurrence observed on follow-up angiograms. Intraoperative indocyanine videoangiography is a less invasive procedure, which could assist the surgeon in reducing the risk for an AVM remnant and help interpret early postoperative angiographic findings. ${ }^{30}$ However, we note that this technique can visualize only superficial abnormal vessels around the resection cavity.

\section{Characteristics of Patients With Recurrence}

The recurrence of an AVM is rare ${ }^{11}$ and affects mostly pediatric patients according to several studies., ${ }^{2,3}$ The results of our series, indicating that all cases of recurrence occurred in children, confirm these earlier findings. However, cases of AVM recurrence in adult patients have

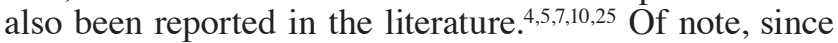
follow-up angiographic monitoring was not performed beyond 1 year after treatment in our adult patients (i.e., those older than 18 years), it is possible that some of these patients actually had recurrent AVMs, even though none of them presented with rebleeding. As recommended by other authors, ${ }^{2}$ pediatric patients treated at our institution are followed up angiographically for several years after treatment. We note, however, that according to some authors, recorded AVM recurrence occurs mainly in the first year after surgery; ${ }^{17}$ therefore, no further angiographic follow-up 1 year after treatment is generally recommended.

Of note, in our series, recurrences were diagnosed on average 18.8 months (range 12 to 42 months) after microsurgery. All the patients in the present study were followed up with conventional angiography between 1 and 2 years after the treatment. Patient 1 had no detectable recurrence on a conventional angiogram 21 months after surgery; however, recurrence in this patient was identified on an angiogram 42 months postsurgery (Table 2), indicating true recurrence. Late AVM recurrences after 1 year were also reported by other authors, ${ }^{21}$ even when angiographic follow-ups during the first year posttreatment did not show AVM recurrence. In a study by Kader et al., later angiographic follow-ups were not systematically performed among patients, a practice that could explain why AVM recurrences in this series became apparent in most cases (i.e., in 3 of 5) when patients presented with hemorrhage. ${ }^{12}$ In another series, ${ }^{14,17}$ as in ours, bleeding from an AVM recurrence was rare, probably because of longer and more regular angiographic follow-ups. Moreover, in the series of Kader and coworkers, ${ }^{12}$ AVM recurrence appeared to occur later than in 2 other reported series (Table 3), ${ }^{14,17}$ as no systematic late angiographic follow-up was conducted after the initial treatment; this observation could also be due to the lack of angiographic follow-ups 1 and 2 years posttreatment.

It is important to weigh the risks and potential benefits of repeated conventional angiography, especially in pediatric patients. Ruling out AVM recurrence is a priority, but, if possible, very frequent angiographic examinations should be avoided to minimize radiation exposure and other risks associated with angiography and anesthesia. We recommend that postoperative angiographic followups after 1 year should be systematically performed in children, including periodic MR angiography examinations, and the last angiographic follow-up should be performed 5 years after the treatment or when the patient reaches adulthood. In adults, we consider 1 angiographic follow-up 1 year after complete resection to be sufficient, but the question of a longer follow-up should be discussed.

\section{Treatment of AVM Recurrence}

A history of hemorrhage is the most widely recognized factor for rebleeding in patients with AVM. ${ }^{13}$ The risk 
TABLE 3. Summary of the main literature reports on AVM recurrence in pediatric patients

\begin{tabular}{|c|c|c|c|c|c|c|c|c|}
\hline Authors \& Year & $\begin{array}{l}\text { Age at } \\
\text { Dx (yrs) }\end{array}$ & Sex & Initial Presentation & $\begin{array}{l}\text { Time From Tx } \\
\text { to Recurrence } \\
\text { (mos) }\end{array}$ & $\begin{array}{l}\text { Recurrence Detection/ } \\
\text { Presentation }\end{array}$ & Venous Drainage & $\begin{array}{l}\text { Tx Modality for } \\
\text { Recurrence }\end{array}$ & $\begin{array}{c}\text { Complete } \\
\text { Obliteration of } \\
\text { Recurrence }\end{array}$ \\
\hline \multirow[t]{5}{*}{ Klimo et al., 2007} & 11 & M & $\mathrm{ICH}$ & 7 & Routine angiography & NS & SRS & No \\
\hline & 12 & M & $\mathrm{ICH}$ & 84 & Seizure & Superficial & MS & Yes \\
\hline & 7 & $\mathrm{~F}$ & $\mathrm{ICH}$ & 7 & Routine angiography & NS & MS & Yes \\
\hline & 1 & $F$ & Nystagmus & 24 & IVH & NS & MS \& SRS & No \\
\hline & 9 & M & ICH \& IVH & 6 & Routine angiography & NS & MS & No \\
\hline \multirow[t]{5}{*}{ Kader et al., 1996} & 8 & $\mathrm{~F}$ & $\mathrm{ICH}$ & 72 & $\mathrm{ICH}$ & NS & MS & Yes \\
\hline & 6 & $\mathrm{~F}$ & Headache \& palsy & 108 & $\mathrm{ICH}$ & Superficial & ET & No \\
\hline & 11 & M & IVH & 36 & $\mathrm{ICH} \& \mathrm{IVH}$ & NA & None & NA \\
\hline & 5 & $\mathrm{~F}$ & $\mathrm{ICH}$ & 84 & Seizure & Superficial & MS & Yes \\
\hline & 12 & $\mathrm{~F}$ & $\mathrm{ICH}$ & 12 & Routine angiography & Deep & SRS & NA \\
\hline \multirow[t]{4}{*}{ Lang et al., 2012} & 12 & NA & $\mathrm{ICH}$ & 13 & Routine angiography & Superficial & MS & NS \\
\hline & 8 & NA & Papilledema & 12 & Routine angiography & Superficial & MS & NS \\
\hline & 5 & NA & $\mathrm{ICH}$ & 11 & Routine angiography & Deep & MS & NS \\
\hline & 15 & NA & Syncope & 10 & Seizure & Superficial \& deep & MS & NS \\
\hline \multirow[t]{7}{*}{ Present study } & 13 & $\mathrm{M}$ & $\mathrm{ICH}$ & 42 & Routine angiography & Superficial & SRS & No \\
\hline & 8 & M & $\mathrm{ICH}$ & 13 & Routine angiography & Deep & SRS & Yes \\
\hline & 11 & $\mathrm{~F}$ & $\mathrm{ICH} \& \mathrm{IVH}$ & 17 & Routine angiography & Superficial & SRS & Yes \\
\hline & 6 & $\mathrm{~F}$ & $\mathrm{ICH} \& \mathrm{IVH}$ & 17 & $\mathrm{ICH}$ & Deep & SRS & Yes \\
\hline & 10 & $\mathrm{M}$ & $\mathrm{ICH}$ & 12 & Routine angiography & Deep & SRS & No \\
\hline & 13 & $\mathrm{~F}$ & $\mathrm{ICH}$ & 12 & Routine angiography & Superficial & SRS & No \\
\hline & 5 & $M$ & $\mathrm{ICH} \& \mathrm{IVH}$ & 18 & Routine angiography & Superficial & MS & Yes \\
\hline
\end{tabular}

$\mathrm{ET}=$ endovascular treatment; ICH = intracerebral hematoma; IVH = intraventricular hematoma; NA = not available; NS = not specified.

for rebleeding persists in cases of AVM recurrence and therefore needs to be addressed through treatment. ${ }^{21}$ In our series, a recurrent AVM caused bleeding in 1 patient. The medical status of the patient, the patient's neurological recovery, and the size and location of the recurring AVM should be taken into account to select an optimal treatment. Morgan and coworkers reported that in their series of 8 patients with AVM recurrence who had all been treated with microsurgery, 1 patient with an SM Grade III AVM died and 1 patient with an SM Grade IV AVM showed worsening in neurological symptoms. ${ }^{21}$ In our series, because of the locations of the ruptured AVMs in eloquent areas in 4 patients and deep venous drainage in 3 patients, the surgical team decided on radiosurgery treatment. However, during the latency period of radiosurgery, the risk for bleeding always persists until total AVM obliteration is achieved. Spontaneous regression of AVM has anecdotally been reported, especially in cases of initial hemorrhagic presentation, small AVM size, and single venous drainage. ${ }^{8,19,20}$ However, considering the seriousness of the risk for rebleeding, we think that aggressive treatments are warranted in case of recurrent AVM.

\section{Conclusions}

Recurrence of AVMs in patients after treatment for ruptured AVMs is rare in adults but not unusual in children. In adults, angiographic follow-up should be performed in the first 2 postoperative weeks and then at 1 year. Conventional angiography after 1 year appears to be sufficient because of the absence of recurrence or late hemorrhage in this group of patients. In children, early angiographic followup is recommended and should also be conducted 1 year after surgery. We propose additional follow-ups with MR or CT angiography every 2 years to detect any AVM recurrence in pediatric patients. If a suspected AVM recurrence is present, a 3D rotational subtracted angiography is mandatory to confirm the diagnosis and to decide on treatment.

For pediatric patients, we recommend a final follow-up with 3D rotational subtracted angiography at the age of 18 years, to detect any persistent or recurrent AVMs. The optimal treatment of AVM recurrence should involve discussion in multidisciplinary surgical team, with the aim of total obliteration of the AVM to ensure that patients are at low future risk for recurring AVMs.

\section{References}

1. Abdulrauf SI, Malik GM, Awad IA: Spontaneous angiographic obliteration of cerebral arteriovenous malformations. Neurosurgery 44:280-288, 1999

2. Ali MJ, Bendok BR, Rosenblatt S, Rose JE, Getch CC, Batjer $\mathrm{HH}$ : Recurrence of pediatric cerebral arteriovenous malformations after angiographically documented resection. Pediatr Neurosurg 39:32-38, 2003

3. Andaluz N, Myseros JS, Sathi S, Crone KR, Tew JM Jr: Recurrence of cerebral arteriovenous malformations in children: report of two cases and review of the literature. Surg Neurol 62:324-331, 2004 
4. Codd PJ, Mitha AP, Ogilvy CS: A recurrent cerebral arteriovenous malformation in an adult. J Neurosurg 109:486-491, 2008

5. Freudenstein D, Duffner F, Ernemann U, Rachinger J, Grote $\mathrm{E}$ : Recurrence of a cerebral arteriovenous malformation after surgical excision. Cerebrovasc Dis 11:59-64, 2001

6. Gaballah M, Storm PB, Rabinowitz D, Ichord RN, Hurst RW, Krishnamurthy G, et al: Intraoperative cerebral angiography in arteriovenous malformation resection in children: a single institutional experience. J Neurosurg Pediatr 13:222-228, 2014

7. Gabriel EM, Sampson JH, Wilkins RH: Recurrence of a cerebral arteriovenous malformation after surgical excision. Case report. J Neurosurg 84:879-882, 1996

8. Guazzo EP, Xuereb JH: Spontaneous thrombosis of an arteriovenous malformation. J Neurol Neurosurg Psychiatry 57:1410-1412, 1994

9. Hetts SW, Cooke DL, Nelson J, Gupta N, Fullerton H, Amans $\mathrm{MR}$, et al: Influence of patient age on angioarchitecture of brain arteriovenous malformations. AJNR Am J Neuroradiol 35:1376-1380, 2014

10. Hino A, Fujimoto M, Iwamoto Y, Takahashi Y, Katsumori T: An adult case of recurrent arteriovenous malformation after "complete" surgical excision: a case report. Surg Neurol 52:156-159, 1999

11. Hladky JP, Lejeune JP, Blond S, Pruvo JP, Dhellemmes P: Cerebral arteriovenous malformations in children: report on 62 cases. Childs Nerv Syst 10:328-333, 1994

12. Kader A, Goodrich JT, Sonstein WJ, Stein BM, Carmel PW, Michelsen WJ: Recurrent cerebral arteriovenous malformations after negative postoperative angiograms. J Neurosurg 85:14-18, 1996

13. Kim H, Al-Shahi Salman R, McCulloch CE, Stapf C, Young WL: Untreated brain arteriovenous malformation: patientlevel meta-analysis of hemorrhage predictors. Neurology 83:590-597, 2014

14. Klimo P Jr, Rao G, Brockmeyer D: Pediatric arteriovenous malformations: a 15-year experience with an emphasis on residual and recurrent lesions. Childs Nerv Syst 23:31-37, 2007

15. Koizumi T, Shiraishi T, Hagihara N, Tabuchi K, Hayashi T, Kawano T: Expression of vascular endothelial growth factors and their receptors in and around intracranial arteriovenous malformations. Neurosurgery 50:117-126, 2002

16. Lagares A, Alen JF, Gomez PA, Lobato RD: Grading of subarachnoid hemorrhage: modification of the World Federation of Neurosurgical Societies scale on the basis of data for a large series of patients. Neurosurgery 56:E873, 2005 (Letter)

17. Lang SS, Beslow LA, Bailey RL, Vossough A, Ekstrom J, Heuer GG, et al: Follow-up imaging to detect recurrence of surgically treated pediatric arteriovenous malformations. J Neurosurg Pediatr 9:497-504, 2012

18. Lawton MT: Spetzler-Martin Grade III arteriovenous malformations: surgical results and a modification of the grading scale. Neurosurgery 52:740-749, 2003

19. Lee SK, Vilela P, Willinsky R, TerBrugge KG: Spontaneous regression of cerebral arteriovenous malformations: clinical and angiographic analysis with review of the literature. Neuroradiology 44:11-16, 2002
20. Minakawa T, Tanaka R, Koike T, Takeuchi S, Sasaki O: Angiographic follow-up study of cerebral arteriovenous malformations with reference to their enlargement and regression. Neurosurgery 24:68-74, 1989

21. Morgan MK, Patel NJ, Simons M, Ritson EA, Heller GZ: Influence of the combination of patient age and deep venous drainage on brain arteriovenous malformation recurrence after surgery. J Neurosurg 117:934-941, 2012

22. Pellettieri L, Svendsen P, Wikholm G, Carlsson CA: Hidden compartments in AVMs-a new concept. Acta Radiol 38:2-7, 1997

23. Rankin J: Cerebral vascular accidents in patients over the age of 60. I. General considerations. Scott Med J 2:127-136, 1957

24. Sano K, Ueda Y, Saito I: Subarachnoid hemorrhage in children. Childs Brain 4:38-46, 1978

25. Santoro A, Giuliani S, Paolini S: Recurrent arteriovenous malformation in an adult. Case illustration. J Neurosurg 93: 1082,2000

26. Sidi A, Lobato EB, Cohen JA: The American Society of Anesthesiologists' Physical Status: category V revisited. J Clin Anesth 12:328-334, 2000

27. Sonstein WJ, Kader A, Michelsen WJ, Llena JF, Hirano A, Casper D: Expression of vascular endothelial growth factor in pediatric and adult cerebral arteriovenous malformations: an immunocytochemical study. J Neurosurg 85:838-845, 1996

28. Spetzler RF, Martin NA: A proposed grading system for arteriovenous malformations. J Neurosurg 65:476-483, 1986

29. van Beijnum J, van der Worp HB, Buis DR, Al-Shahi Salman R, Kappelle LJ, Rinkel GJ, et al: Treatment of brain arteriovenous malformations: a systematic review and meta-analysis. JAMA 306:2011-2019, 2011

30. Zaidi HA, Abla AA, Nakaji P, Chowdhry SA, Albuquerque FC, Spetzler RF: Indocyanine green angiography in the surgical management of cerebral arteriovenous malformations: lessons learned in 130 consecutive cases. Neurosurgery 10 (Suppl 2):246-251, 2014

\section{Disclosures}

The authors report no conflict of interest concerning the materials or methods used in this study or the findings specified in this paper.

\section{Author Contributions}

Conception and design: Aboukaïs, Vinchon, Lejeune. Acquisition of data: all authors. Analysis and interpretation of data: Aboukaïs, Lejeune. Critically revising the article: Aboukaïs, Quidet. Reviewed submitted version of manuscript: Aboukaïs, Vinchon, Lejeune. Study supervision: Vinchon, Bourgeois, Leclerc, Lejeune.

\section{Correspondence}

Rabih Aboukaïs, Department of Neurosurgery, Lille University Hospital, rue E. Laine, 59037 Lille cedex, France. email: rabihdoc@hotmail.com. 